\title{
Applying Composites in Concrete Repair Engineering
}

\author{
Hengze Chen, ${ }^{1}$ Hongbo Zhang, ${ }^{2}$ and Wei-Ling $\mathrm{Hsu}^{2 *}$ \\ ${ }^{1}$ Faculty of Architecture and Civil Engineering, Huaiyin Institute of Technology, \\ No. 1 Meicheng East Road, Huai'an City, Jiangsu 223003, China \\ ${ }^{2}$ Institute of Land and Urban-Rural Planning, School of Urban and Environmental Science, \\ Huaiyin Normal University, No. 111 Changjang West Rd., Huai'an City, Jiangsu 223300, China
}

(Received May 10, 2019; accepted October 8, 2019)

Keywords: concrete, polymer elastomer, repair strength

To construct road pavements, rigid cement, where has a wide range of applications is often adopted; however, cement pavements have disadvantages in terms of their use and dependence on environmental conditions, roadbed construction quality, and material quality. In this study, we investigated a concrete repair material and its preparation method as well as its application in concrete repair engineering. Advanced sensing instruments were used to detect the health of concrete. The repair material has the combined characteristics of concrete, polymer elastomer, exothermic material, and heat-change material, namely, excellent early strength performance, UV light resistance, and repair strength.

\section{Introduction}

Concrete pavement has exceptional workability and durability as well as advantages such as strong structure, high load-diffusion capability, high frictional resistance, favorable slip resistance, high wear resistance, high temperature and water stability, long service life, and low maintenance cost. However, it also has several disadvantages, for example, critical defects such as flaws in their use and dependence on environmental conditions, roadbed construction quality, and material quality, which causes various types and severities of local damage including cracking, slab breakage, partial depression or faulting of slab ends, loosening and partial breakage into small pieces, peeling, partial loosening that causes potholes, scum formation, exposure, and surface pitting. Because early partial damage of concrete pavement results in severe consequences, the exploration of materials and methods for the rapid repair of cement concrete is of great importance to the development and use of concrete pavement.

Advanced material sensors such as heat-change material, concrete epoxy-polyurethane, and UV light monitors were applied to measure the concrete and epoxy-polyurethane materials to establish the relevant qualities of concrete, cement mortar, and adhesive. Appropriate countermeasures were explored to solve the problem of repairing concrete cracks in this study. We found that quartz sand and river sand could be employed as base materials and could provide the repair material with sufficient strength after curing. Epoxy-polyurethane composite has a

*Corresponding author: e-mail: quartback@hotmail.com

https://doi.org/10.18494/SAM.2019.2451 
certain level of fluidity and favorable elasticity, thereby giving the repair material high strength after curing.

The rest of the paper is organized as follows. In Sect. 2, we extensively review the latest literature concerning the characteristics of concrete composites and the sustainable development of concrete materials. In Sect. 3, we describe examples of implementation and experimental comparisons of the materials. In Sect. 4, we discuss the repair experiment and the effects of the characteristics of the different component materials on the repair performance. Finally, in Sect. 5, we summarize the conclusions of this study and future research recommendations.

\section{Literature Review}

According to statistics compiled in the United States and Japan, the demand for reinforced concrete structures has risen sharply. However, because of the intensive growth of the construction industry in large-area construction, ${ }^{(1)}$ the reinforcement and repair of concrete structures have come to cover a wide range of areas, with different structures having distinct characteristics and needs. This is primarily due to the growth of the production and transportation industries as well as large areas being adopted for storage purposes. Therefore, to ensure that paved spaces can withstand greater loads, epoxy resin is often used as a concrete surface coating. ${ }^{(2,3)}$

\subsection{Characteristics of concrete composites}

High-early-strength concrete can be prepared by three approaches: the use of early-strength cement that hardens rapidly, early-strength agents, or various additives and admixtures containing special minerals. Tang et al. reviewed the latest research on concrete durability and suggested a novel approach to accurately estimating the durability and service life of concrete structures. ${ }^{(4)}$ The combination of related components and rebar corrosion is considered to be the key cause of the deterioration of concrete structures. ${ }^{(5)}$ Zhang et al. obtained test results for corroded concrete beams that had been exposed to chloride ions for 14 or 23 years and proposed a relationship between chloride exposure and concrete beam failure. ${ }^{(6)}$ Concrete structures often crack when they have high salt contents, are shaken by an earthquake, are exposed to water vapor, or undergo chloride ion erosion, and cracks lead to rebar oxidation and corrosion as well as damage and spalling. Damaged structures are conventionally repaired using epoxy resin mortar, but this does not involve cleaning the rusted part of the rebar deep within the structure, thereby resulting in prolonged oxidation. Consequently, damage and spalling on the structures continue owing to the volume expansion of the oxidizing rebar, making future repair impossible. ${ }^{(7)}$ Increasing the amount of water in a cement mix results in effective mixing and produces a cement concrete with high fluidity; however, an excessive amount of water tends to cause the formation of numerous pores within the cement stone or on the aggregate interface area, which is the major cause of poor concrete performance. Lin stated that coating recycled aggregates with a slag composite is an effective approach to improving the mechanical properties and durability of recycled concrete. ${ }^{(8)}$ Composites and fiber-reinforced polymers 
are increasingly used to reinforce and repair reinforced concrete beams with the objective of increasing or restoring the bending and shearing capabilities of the beams. ${ }^{(9)}$ Additionally, polymer elastomers are used to enhance the fire resistance of concrete structures. ${ }^{(10)}$ Most construction workers follow the specified composition standards when mixing cement mortar for proportioning design; however, some construction workers increase the sand content. ${ }^{(11)}$ The inorganic materials currently used to repair cracks cannot penetrate the cracks effectively and cause the problem of low strength, which restricts concrete repair works.

\subsection{Sustainable development of concrete materials}

The cement used in construction engineering is usually considered a resource-intensive material. Zero-carbon buildings are currently the ultimate goal of engineering applications and are defined as buildings with zero annual net energy consumption or carbon emissions. Such buildings are regarded as a crucial mainstream construction sector for sustainable development in the future. ${ }^{(12)}$ The growth of the production and transportation industries and the adaptation of large concrete areas for storage purposes have led to the increased production of polymer elastomers, and epoxy resin plays a major role in ensuring that concrete structures can withstand greater loads. ${ }^{(2,3)}$ The use of composites to extend the life of concrete structures is a crucial topic for environmental sustainability.

\section{Materials and Methods}

\subsection{Implementation example 1}

\subsubsection{Preparation of epoxy-polyurethane composites (EPC-1)}

Step 1 is the preparation of fluorine-modified acrylic resin. Calculated by weight, 15 portions of xylene and 18 portions of butyl acetate were mixed to form a mixed solvent, which was heated to $90{ }^{\circ} \mathrm{C}$. Subsequently, 14 portions of styrene, 10 portions of methyl methacrylate, 24 portions of butyl acrylate, 8 portions of acrylic acid, 5 portions of dodecafluoroheptyl methacrylate, 0.5 portions of benzoyl peroxide, 5 portions of xylene, and 12 portions of butyl acetate were evenly mixed to form a monomer mixture. The monomer mixture was added dropwise to the mixed solvent to undergo thermal insulation reaction for $4 \mathrm{~h}$. The material filtered from the cooled product was fluorine-modified acrylic resin.

Step 2 is the preparation of modified epoxy resin. Calculated by weight, 50 portions of E44 epoxy resin were heated to $70{ }^{\circ} \mathrm{C}$, and 20 portions of fluorine-modified acrylic resin and 1 portion of trimethylamine (catalyst) were added dropwise to the epoxy resin. The temperature was then increased to $100{ }^{\circ} \mathrm{C}$, and the reaction was continued for $1 \mathrm{~h}$, after which the material was cooled and filtered to derive the modified epoxy resin.

Step 3 is the preparation of polyurethane prepolymer. Calculated by weight, 15 portions of polypropylene glycol were heated to $50{ }^{\circ} \mathrm{C}$, after which 10 portions of toluene diisocyanate were added dropwise. The temperature of the mixture was then increased to $80^{\circ} \mathrm{C}$, and the reaction was continued for $2 \mathrm{~h}$; polyurethane prepolymer was obtained after cooling. 
Step 4 is the preparation of EPC-1. Calculated by weight, 25 portions of modified epoxy resin, 30 portions of polyurethane prepolymer, 0.3 portions of azobisisobutyronitrile (initiator), 2 portions of ethylenediamine, and 30 portions of nanosilica were subjected to cross-linking reaction at $70{ }^{\circ} \mathrm{C}$ for $3 \mathrm{~h}$. The resulting product obtained was EPC-1.

\subsubsection{Preparation of heat-change material (HCM-1) and concrete repair material}

Calculated by weight under a nitrogen atmosphere, 30 portions of $\mathrm{N}$-isopropyl acrylamide, 3 portions of $\mathrm{N}, \mathrm{N}^{\prime}$ methylenebisacrylamide, 0.2 portions of 2-ketoglutaric acid (photoinitiator), and 240 portions of water were mixed evenly. Photoinitiated polymerization was then conducted under UV light irradiation at $35^{\circ} \mathrm{C}$ for $2 \mathrm{~h}$ to obtain HCM-1.

The concrete repair material was prepared through the following steps.

Step 1: Thirty portions of sulphoaluminate cement, 8 portions of quartz sand, 8 portions of river sand (particle size: $1-2 \mathrm{~mm}$ ), and 3 portions of $\mathrm{HCM}-1$ were mixed at $35^{\circ} \mathrm{C}$ for $20 \mathrm{~min}$.

Step 2: Twenty portions of EPC-1, 2 portions of sulfanilic acid (water-reducing agent), 0.6 portions of alkylbenezenesulfonate (anionic surface-active agent), and 2 portions of borax (retarder) were uniformly mixed with the mixture from Step 1 at $25{ }^{\circ} \mathrm{C}$ for $10 \mathrm{~min}$.

Step 3: Two portions of calcium oxide were mixed with the mixture from Step 2 at $20{ }^{\circ} \mathrm{C}$ for $10 \mathrm{~min}$.

The common particle size specifications of quartz sand are $0.5-1,1-2,2-4$, and $4-8 \mathrm{~mm}$. The effect of the quartz sand particle size on the repair performance was analyzed.

Application of the prepared concrete repair material: The concrete repair material was mixed uniformly with water in the weight ratio $4-5: 0.2-0.3$. The mixture was then used to fill concrete cracks and cured for 7-10 days.

This prepared concrete repair material was also used in the following implementation and comparative examples.

\subsection{Implementation example 2}

\subsubsection{Preparation of epoxy-polyurethane composite (EPC-2)}

Step 1 is the preparation of fluorine-modified acrylic resin. Calculated by weight, 15 portions of xylene and 18 portions of butyl acetate were mixed to form a mixed solvent and heated to $90{ }^{\circ} \mathrm{C}$. Subsequently, 12 portions of styrene, 5 portions of methyl methacrylate, 20 portions of butyl acrylate, 6 portions of acrylic acid, 3 portions of dodecafluoroheptyl methacrylate, 0.5 portions of benzoyl peroxide, 10 portions of xylene, and 15 portions of butyl acetate were mixed uniformly to yield a monomer mixture. The monomer mixture was then added dropwise to the mixed solvent to induce thermal insulation reactions for $4 \mathrm{~h}$. The material was cooled and filtered to obtain the fluorine-modified acrylic resin.

Step 2 is the preparation of modified epoxy resin. Calculated by weight, 50 portions of E44 epoxy resin were heated to $70{ }^{\circ} \mathrm{C}$. Subsequently, 20 portions of fluorine-modified acrylic resin and 1 portion of trimethylamine (catalyst) were added dropwise to the epoxy resin. The 
temperature was then increased to $100{ }^{\circ} \mathrm{C}$, and the reaction was continued for $1-2 \mathrm{~h}$, after which the material was cooled and filtered to derive the modified epoxy resin.

Step 3 is the preparation of polyurethane prepolymer. Calculated by weight, 15 portions of polypropylene glycol were heated to $50^{\circ} \mathrm{C}$, after which 10 portions of toluene diisocyanate were added dropwise. The temperature of the mixture was then increased to $70{ }^{\circ} \mathrm{C}$, and the reaction was continued for $1 \mathrm{~h}$, with the polyurethane prepolymer being obtained after cooling.

Step 4 is the preparation of EPC-2. Calculated by weight, 25 portions of modified epoxy resin, 30 portions of the polyurethane prepolymer, 0.5 portions of azobisisobutyronitrile (initiator), 4 portions of ethylenediamine, and 30 portions of nanosilica were subjected to cross-linking reaction at $70{ }^{\circ} \mathrm{C}$ for $3 \mathrm{~h}$. The product obtained was EPC-2.

\subsubsection{Preparation of heat-change material (HCM-2) and concrete repair material}

Calculated by weight under a nitrogen atmosphere, 20 portions of $\mathrm{N}$-isopropyl acrylamide, 1-3 portions of N, N'-methylenebisacrylamide, 0.2 portions of 2-ketoglutaric acid (photoinitiator), and 180 portions of water were mixed evenly. Photoinitiated polymerization was then conducted under UV light irradiation at $25^{\circ} \mathrm{C}$ for $2 \mathrm{~h}$ to obtain HCM-2.

The concrete repair material was prepared through the following steps:

Step 1: Thirty portions of sulphoaluminate cement, 8 portions of quartz sand (particle size: 2-4 mm), 6 portions of river sand (particle size: $1-2 \mathrm{~mm}$ ), and 3 portions of HCM-2 were mixed at $35^{\circ} \mathrm{C}$ for $20 \mathrm{~min}$.

Step 2: Ten to twenty-five portions of EPC-2, 3 portions of sulfanilic acid (water-reducing agent), 0.6 portions of alkylbenezenesulfonate (anionic surface-active agent), and 1 portion of borax (retarder) were uniformly mixed with the mixture from Step 1 at 25 ${ }^{\circ} \mathrm{C}$ for $15 \mathrm{~min}$.

Step 3: Two portions of calcium oxide were mixed with the mixture from Step 2 at $25{ }^{\circ} \mathrm{C}$ for $15 \mathrm{~min}$.

The effect of the amount of EPC-2 on the repair performance was investigated.

\subsection{Experimental comparison}

\subsubsection{Comparative example 1}

The difference of this example from implementation example 1 was that the river sand was replaced by quartz sand.

Preparation of epoxy-polyurethane composite: The preparation method was the same as that in implementation example 1.

Preparation of heat-change material: The preparation method was the same as that in implementation example 1.

The concrete repair material was prepared through the following steps.

Step 1: Thirty portions of sulphoaluminate cement, 16 portions of quartz sand (particle size: 2-4 mm), and 3 portions of $\mathrm{HCM}-1$ were mixed at $35^{\circ} \mathrm{C}$ for $20 \mathrm{~min}$. 
Step 2: Twenty portions of EPC-1, 2 portions of sulfanilic acid (water-reducing agent), 0.6 portions of alkylbenezenesulfonate (anionic surface-active agent), and 2 portions of borax (retarder) were mixed with the mixture from Step 1 at $25^{\circ} \mathrm{C}$ for $10 \mathrm{~min}$.

Step 3: Two portions of calcium oxide were mixed with the mixture from Step 2 at $20{ }^{\circ} \mathrm{C}$ for 15 min.

\subsubsection{Comparative example 2}

The difference of this example from implementation example 1 was that the acrylic acid in the epoxy-polyurethane material was not modified with fluorine-containing monomer.

Preparation of EPC-3:

Step 1 is the preparation of modified acrylic resin. Calculated by weight, 15 portions of xylene and 18 portions of butyl acetate were mixed to form a mixed solvent, which was heated to $90{ }^{\circ} \mathrm{C}$. Subsequently, 14 portions of styrene, 10 portions of methyl methacrylate, 24 portions of butyl acrylate, 8 portions of acrylic acid, 0.5 portions of benzoyl peroxide, 5 portions of xylene, and 12 portions of butyl acetate were mixed uniformly to yield a monomer mixture. The monomer mixture was then added dropwise to the mixed solvent to induce thermal insulation reactions for $4 \mathrm{~h}$, and the product was cooled and filtered to derive the modified acrylic resin.

Step 2 is the preparation of modified epoxy resin. Calculated by weight, 50 portions of E44 epoxy resin were heated to $70{ }^{\circ} \mathrm{C}$, after which 20 portions of modified acrylic resin and 1 portion of trimethylamine (catalyst) were added dropwise. The temperature was then increased to $100{ }^{\circ} \mathrm{C}$, and the reaction was continued for $1 \mathrm{~h}$, after which the material filtered from the cooled product was harvested as the modified epoxy resin.

Step 3 is the preparation of polyurethane prepolymer. Calculated by weight, 15 portions of polypropylene glycol were heated to $50^{\circ} \mathrm{C}$, after which 10 portions of toluene diisocyanate were added dropwise. The temperature of the mixture was then increased to $80^{\circ} \mathrm{C}$, and the reaction was continued for $2 \mathrm{~h}$. Polyurethane prepolymer was obtained after cooling.

Step 4 is the preparation of EPC-3. Calculated by weight, 25 portions of modified epoxy resin, 30 portions of polyurethane prepolymer, 0.3 portions of azobisisobutyronitrile (initiator), 2 portions of ethylenediamine, and 30 portions of nanosilica underwent cross-linking reaction at $70{ }^{\circ} \mathrm{C}$ for $3 \mathrm{~h}$. The product obtained was EPC-3.

Preparation of heat-change material: The preparation method was the same as that in implementation example 1.

The concrete repair material was prepared through the following steps.

Step 1: Thirty portions of sulphoaluminate cement, 8 portions of quartz sand (particle size: 2-4 mm), 8 portions of river sand (particle size: $1-2 \mathrm{~mm}$ ), and 3 portions of HCM-1 were mixed at $35^{\circ} \mathrm{C}$ for $20 \mathrm{~min}$.

Step 2: Twenty portions of EPC-3, 2 portions of sulfanilic acid (water-reducing agent), 0.6 portions of alkylbenezenesulfonate (anionic surface-active agent), and 2 portions of borax (retarder) were mixed with the mixture from Step 1 at $25^{\circ} \mathrm{C}$ for $10 \mathrm{~min}$.

Step 3: Two portions of calcium oxide were mixed with the mixture from Step 2 at $20{ }^{\circ} \mathrm{C}$ for $10 \mathrm{~min}$. 


\subsubsection{Comparative example 3}

The difference of this example from implementation example 1 was that no exothermic material was added.

Preparation of epoxy-polyurethane composite: The preparation method was the same as that in implementation example 1.

Preparation of heat-change material: The preparation method was the same as that in implementation example 1.

The concrete repair material was prepared through the following steps.

Step 1: Thirty portions of sulphoaluminate cement, 8 portions of quartz sand (particle size: 2-4 mm), 8 portions of river sand (particle size: $1-2 \mathrm{~mm}$ ), and 3 portions of HCM-1 were mixed at $35{ }^{\circ} \mathrm{C}$ for $20 \mathrm{~min}$.

Step 2: Twenty portions of EPC-1, 2 portions of sulfanilic acid (water-reducing agent), 0.6 portions of alkylbenezenesulfonate (anionic surface-active agent), and 2 portions of borax (retarder) were mixed with the mixture from Step 1 at $25^{\circ} \mathrm{C}$ for $10 \mathrm{~min}$.

\subsubsection{Comparative example 4}

In this example, the difference from implementation example 1 was that no exothermic material was added.

Preparation of epoxy-polyurethane composite: The preparation method was the same as that in implementation example 1.

The concrete repair material was prepared through the following steps.

Step 1: Thirty portions of sulphoaluminate cement, 8 portions of quartz sand (particle size: 2-4 mm), and 8 portions of river sand (particle size: $1-2 \mathrm{~mm}$ ) were mixed at $35^{\circ} \mathrm{C}$ for $20 \mathrm{~min}$.

Step 2: Twenty portions of EPC-1, 2 portions of sulfanilic acid (water-reducing agent), 0.6 portions of alkylbenezenesulfonate (anionic surface-active agent), and 2 portions of borax (retarder) were mixed with the mixture from Step 1 at $25^{\circ} \mathrm{C}$ for $10 \mathrm{~min}$.

Step 3: Two portions of calcium oxide were mixed with the mixture from Step 2 at $20{ }^{\circ} \mathrm{C}$ for $10 \mathrm{~min}$.

\section{Discussion}

\subsection{Repair experiment}

\subsubsection{Sample}

A concrete test block with gaps was used and the flection specimen was a long strip. The dimensions of the specimen mold were $120 \times 15 \times 10 \mathrm{~mm}^{3}$. The prepared repair material was injected into the mold of the bending specimen, sealed, and cured at room temperature for 7 days. 


\subsubsection{Flexural and tensile strengths}

The status and dimensions of the flection specimen were the same as those of the tensile specimen. The tensile specimen was dumbbell-shaped, and its total length, midsection length, end width, midsection width, transition arc radius, thickness, and fixture distance were 170, 55, $20,10,75,10$, and $110 \mathrm{~mm}$, respectively.

The flexural and tensile strengths of the cured flection and tensile specimens were measured using a CSS-2205 electronic universal testing machine. The tests of flexural and tensile strengths were conducted in accordance with GB1040-79, and flexural strength was measured using a static three-point load. The specimens were placed on two supports and a concentrated load was applied to the specimens at the center of the supports at a speed of $50 \mathrm{~mm} / \mathrm{min}$ to cause flexural stress and deformation. The tensile strength of a specimen was measured by applying a tensile load along the axial direction of the specimen at a speed of $50 \mathrm{~mm} / \mathrm{min}$ to cause damage.

\subsubsection{Bond strength}

Flexural strength was adopted as an indicator of bond strength. First, a $40 \times 40 \times 160 \mathrm{~mm}^{3}$ mortar specimen was broken using a bending machine. The broken specimen was then put back together into its original shape, with a gap of 3-4 $\mathrm{mm}$ created between two surfaces. Subsequently, three sides of the mortar specimen were sealed and fixed with tapes, and the prepared repair material was injected from the unsealed side, after which the specimen was set aside for 8-10 min. After the gap had been filled and the repair material had been cured at room temperature, the flexural strength of the specimen was tested, and the condition of the new cross section was observed.

\subsubsection{Accelerated aging test using UV light}

An artificial aging test was conducted using UV light in accordance with the specifications of GB/T16422.3-1997. Fluorescent UV light with a wavelength of $285 \mathrm{~nm}$ and a power of $30 \mathrm{~W}$ was employed. The specimen was irradiated with UV light at an approximate distance of $50 \mathrm{~cm}$ for 30 days, after which the effects on the flexural and tensile strengths, and thus the antiaging capacity of the specimen, were determined.

\subsubsection{Thermal cycle test}

The repair materials were maintained at room temperature (approximately $15{ }^{\circ} \mathrm{C}$ ) for 30 min, after which it was immediately placed in a $-20{ }^{\circ} \mathrm{C}$ freezer for $30 \mathrm{~min}$; this formed a cycle that was performed 100 times. Subsequently, the thermal shock properties of the material were tested by examining its flexural and tensile strengths while observing whether any blistering, peeling, delaminating, or cracking of the surface had occurred. 


\subsection{Effect of base particle size on performance of repair materials}

The repair materials prepared using quartz sand particles of various sizes under different conditions in implementation example 1 yielded the sample performance data shown in Table 1. Table 1 indicates that the aggregate particle size affected the strength of the repair material. Using quartz sand particles with sizes of 2-4 $\mathrm{mm}$ resulted in specimens with greater tensile and flexural strengths, and this greater flexural strength was retained after UV-induced and thermal damage, a result that was superior to those with other particle sizes.

\subsection{Effect of amount of epoxy-polyurethane composite on performance of repair materials}

The repair materials prepared with different amounts of epoxy-polyurethane composite under different conditions in implementation example 2 yielded the performance data shown in Table 2. Figure 1 shows plots of the tensile and flexural strengths versus amount of epoxypolyurethane composite. Favorable tensile and flexural strengths were obtained when the amount of composite used was 20 portions. This was primarily because the composite could fill the gaps in the concrete and was compatible with the base material, giving the material high flexural and tensile strengths after its curing.

\subsection{Effects of various preparation materials on performance of repair material}

The materials prepared with quartz sand particles of 2-4 $\mathrm{mm}$ size (implementation example 1) were employed, and the materials in comparative examples $1-4$ were subjected to repair tests. The results are presented in Table 3.

Table 1

Performance of repair materials prepared with quartz sand particles of various sizes.

\begin{tabular}{lcccc}
\hline Particle size & $0.5-1 \mathrm{~mm}$ & $1-2 \mathrm{~mm}$ & $2-4 \mathrm{~mm}$ & $4-8 \mathrm{~mm}$ \\
\hline Tensile strength (MPa) & 43 & 40 & 51 & 40 \\
Flexural strength (MPa) & 74 & 78 & 93 & 81 \\
Bond strength (MPa) & 8.47 & 8.95 & 10.24 & 9.37 \\
Tensile strength retention rate after UV damage (\%) & 97.4 & 98.2 & 98.6 & 93.1 \\
Flexural strength retention rate after UV damage (\%) & 94.1 & 94.8 & 98.2 & 94.3 \\
Tensile strength retention rate after thermal cycle damage (\%) & 83.8 & 90.5 & 91.3 & 88.6 \\
Flexural strength retention rate after thermal cycle damage (\%) & 86.5 & 87.3 & 92.4 & 89.7 \\
\hline
\end{tabular}

Table 2

Performance of repair materials prepared with different amounts of epoxy-polyurethane composite.

\begin{tabular}{lcccc}
\hline Amount of epoxy-polyurethane composite & 10 portions & 15 portions & 20 portions & 25 portions \\
\hline Tensile strength (MPa) & 25 & 32 & 51 & 43 \\
Flexural strength (MPa) & 57 & 69 & 93 & 78 \\
Bond strength (MPa) & 6.25 & 7.11 & 10.24 & 8.72 \\
Tensile strength retention rate after UV damage (\%) & 89.7 & 92.1 & 98.6 & 93.5 \\
Flexural strength retention rate after UV damage (\%) & 85.6 & 90.7 & 98.2 & 92.4 \\
Tensile strength retention rate after thermal cycle damage (\%) & 82.6 & 81.4 & 91.3 & 86.8 \\
Flexural strength retention rate after thermal cycle damage (\%) & 82.9 & 83.4 & 92.4 & 84.9 \\
\hline
\end{tabular}




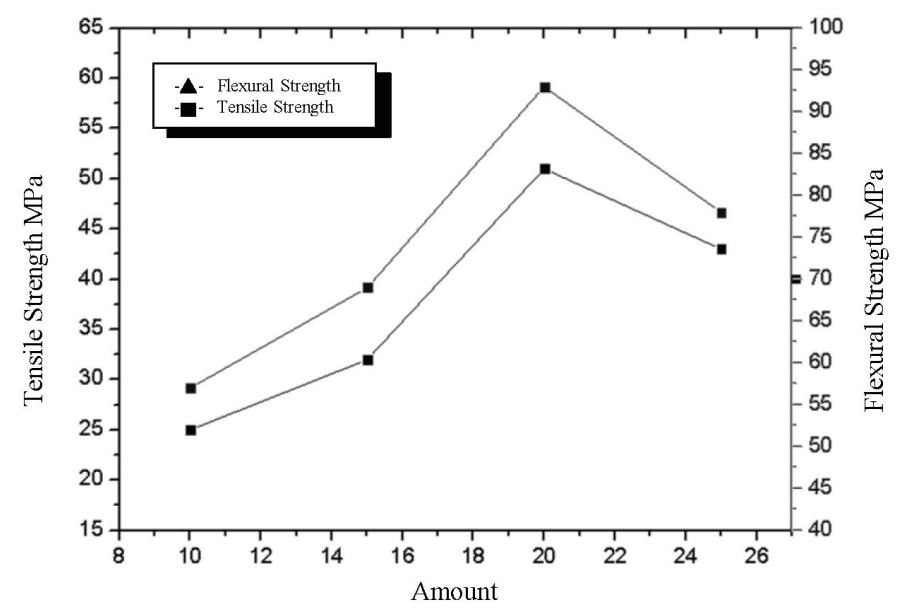

Fig. 1. Effect of amount of epoxy-polyurethane composite on performance of repair material.

Table 3

Characterization of materials with various amounts and particle sizes of quartz sand.

\begin{tabular}{|c|c|c|c|c|c|}
\hline Experimental group & $\begin{array}{l}\text { Implementation } \\
\text { example } 1\end{array}$ & $\begin{array}{l}\text { Comparative } \\
\text { example } 1\end{array}$ & $\begin{array}{l}\text { Comparative } \\
\text { example } 2\end{array}$ & $\begin{array}{c}\text { Comparative } \\
\text { example } 3\end{array}$ & $\begin{array}{c}\text { Comparative } \\
\text { example } 4\end{array}$ \\
\hline Tensile strength (MPa) & 51 & 42 & 49 & 42 & 38 \\
\hline Flexural strength (MPa) & 93 & 84 & 92 & 73 & 68 \\
\hline Bond strength (MPa) & 10.24 & 7.54 & 10.07 & 5.86 & 5.30 \\
\hline $\begin{array}{l}\text { Tensile strength retention rate } \\
\text { after UV damage }(\%)\end{array}$ & 98.6 & 92.3 & 87.4 & 95. & 94.7 \\
\hline $\begin{array}{l}\text { Flexural strength retention rate } \\
\text { after UV damage (\%) }\end{array}$ & 98.2 & 91.6 & 82.7 & 93.2 & 92.3 \\
\hline $\begin{array}{l}\text { Tensile strength retention rate } \\
\text { after thermal cycle damage (\%) }\end{array}$ & 91.3 & 86.2 & 90.5 & 90.6 & 87.4 \\
\hline $\begin{array}{l}\text { Flexural strength retention rate } \\
\text { after thermal cycle damage }(\%)\end{array}$ & 92.4 & 84.9 & 91.7 & 91.3 & 86.8 \\
\hline
\end{tabular}

The comparison of implementation example 1 with comparative example 1 revealed that river sand, with its small particle size, could fill the inner space in quartz sand, yielding a cured specimen with greater flexural and tensile strengths. Figure 2 illustrates the effect of the quartz sand particle size on the repair effect. The comparison of implementation example 1 with comparative example 2 demonstrated that because the modified epoxy-polyurethane material did not include a fluorine-containing monomer, its tensile and flexural strengths were considerably lower than those of the implementation example 1 material after the UV-induced damage test. Thus, the modified composite enhanced the strength of the concrete repair material after curing. Comparison of implementation example 1 with comparative example 3 revealed that when the calcium oxide component (heated up upon contact with water) was not used, the heat-change material was unable to integrate the aggregates and composite effectively through thermal change and did not fill the gaps.

Therefore, the repair material had unsatisfactory strength after curing. From the comparison between implementation example 1 and comparative example 4, the application of the heatchange material increased the repair strength of the repair material. Low repair strength is 


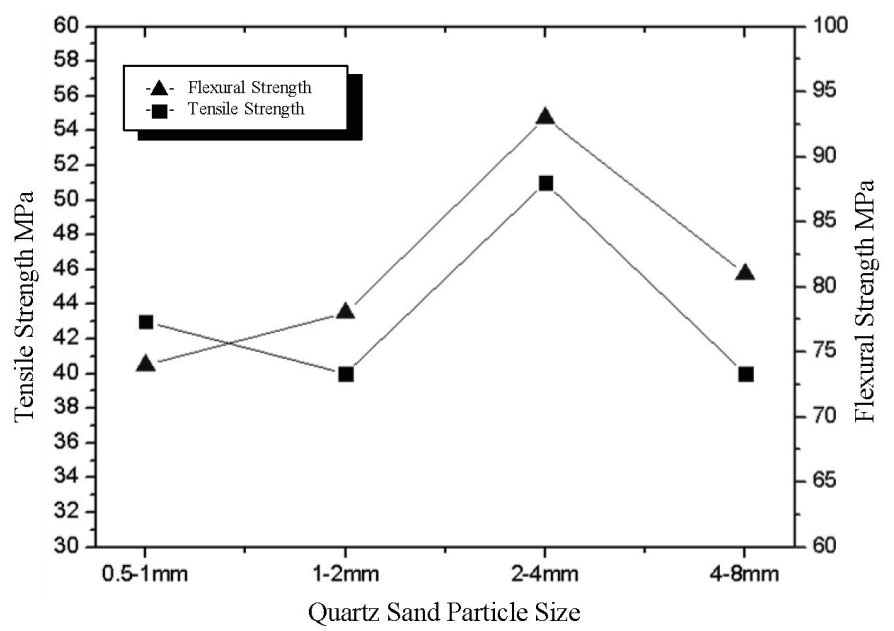

Fig. 2. Effect of quartz sand particle size on performance of repair material.

common in conventional organic-inorganic composites because of problems such as their incapacity to fill the gaps in concrete and the presence of gaps between repair materials. Figure 1 shows the effect of the amount of epoxy-polyurethane composite on the performance of the repair material.

\section{Conclusion}

As the materials used for repairing concrete cracks in this study, quartz sand and river sand were first employed as base materials and were discovered to provide the repair material with sufficient strength after curing. Epoxy-polyurethane composite had a certain degree of fluidity and favorable elasticity, which enabled the repair material to maintain some fluidity in the initial stage and uniformly fill the concrete gaps, thereby giving the material high strength after curing. Additionally, the epoxy resin in the composite was modified using fluorine-modified acrylic acid, which improved the durability of the repair material under UV light irradiation. Exothermic and heat-change materials were jointly used in this study. The exothermic material released heat upon contact with water, whereas the heat-change material contained the monomer $\mathrm{N}$-isopropyl acrylamide, causing it to contract after being heated. After its initial addition to a concrete crack, the heat-change material shrank and left enough space for other polymers and base materials to flow into the gaps, enabling the gap to hold more base materials and polymers. Subsequently, the heat-change material expanded after the heat had dissipated, causing the base materials and polymers to fill the cracks and achieve high repair strength. Further research should be carried out for 5-10 years before the repair material can be commercialized.

\section{References}

1 K. Krzywiński and Ł. Sadowski: Coatings 9 (2019) 143. https://doi.org/10.3390/coatings9020143

2 M. Gruszczyński: Mater. Budow. 9 (2018) 30. https://doi.org/10.15199/33.2018.09.08

3 Ł. Sadowski: Adh. Lay. Cem. Com. (Springer, Switzerland, 2019). https://doi.org/10.1007/978-3-030-03783-3 
4 S. W. Tang, Y. Yao, C. Andrade, and Z. Li: Cement Concrete Res. 78 (2015) 143. https://doi.org/10.1016/ j.cemconres.2015.05.021

5 Y. Zhao and W. Jin: Steel Corrosion-induced Concrete Cracking (Butterworth-Heinemann, Oxford, UK, 2016). https://doi.org/10.1016/B978-0-12-809197-5.00002-5

6 R. Zhang, A. Castel, and R. François: Cement Concrete Res. 40 (2010) 415. https://doi.org/10.1016/ j.cemconres.2009.09.026

7 W.-L. Hsu, C.-C. Liu, Y.-C. Shiau, and W.-C. Lin: Sustainability 11 (2019) 1756. https://doi.org/10.3390/ su11061756

8 W.-T. Lin: Sens. Mater. 30 (2018) 479. https://doi.org/10.18494/SAM.2018.1747

9 M. Valluzzi, E. Grinzato, C. Pellegrino, and C. Modena: Mater. Struct. 42 (2009) 25. https://doi.org/10.1617/ s11527-008-9364-Z

10 H.-J. Chen, Y.-C. Yang, C.-W. Tang, and C.-F. Peng: Sens. Mater. 29 (2017) 523. https://doi.org/10.18494/ SAM.2017.1534

11 W.-L. Hsu, C.-C. Liu, Y.-C. Shiau, C.-L. Wang, and W.-C. Lin: Sens. Mater. 31 (2019) 1071. https://doi. org/10.18494/SAM.2019.2219

12 T. S. Ng, R. M. Yau, T. N. Lam, and V. S. Cheng: Int. J. Low-Carbon Technol. 11 (2016) 222. https://doi. org/10.1093/ijlct/ctt067

\section{About the Authors}

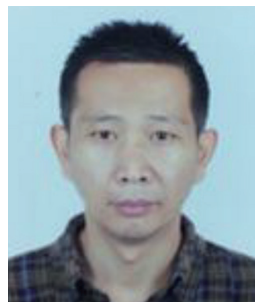

Hengze Chen is a master degree holder and a senior architect, who graduated from Tsinghua University, China majoring in architecture and civil engineering. He is currently a lecturer at the Faculty of Architecture and Civil Engineering, Huaiyin Institute of Technology, China. He is also a national first-level registered architect and is mainly engaged in architectural design, education, and research work. (hycbt@126.com)

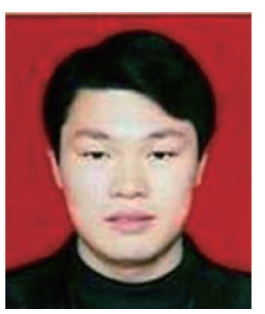

Hongbo Zhang is a master degree holder and a lecturer, who graduated from Jiangsu University with a major in architecture and civil engineering. He is currently a Ph.D. student at the School of Management, China University of Mining and Technology. He is the head of the Department of Real Estate and Engineering Valuation, School of Urban and Environmental Science, Huaiyin Normal University, China. He is also a national registered cost engineer and a first-level construction engineer, and is mainly engaged in engineering economics and engineering project management research and education. (wangdongzhangxi@126.com)

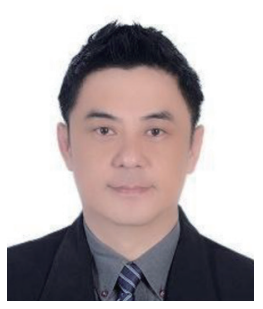

Wei-Ling Hsu received his Ph.D. in 2014 from the Department of Civil Engineering and his Master's degree in architecture in 2009 from Chung Hua University in Taiwan. From 2009 to 2017, he was an adjunct assistant professor at Chung Hua University. He is currently an associate professor at the School of Urban and Environmental Science, Huaiyin Normal University, China. His research expertise includes the application of satellites and unmanned aerial vehicles in ground-level environmental monitoring, urban traffic, urban and rural planning, and the incorporation of data analysis in fuzzy multiple criteria decision making for cities and environments. 